\title{
ANÁLISE ESPACIAL DA REDUÇÃO DA QUEIMA NA COLHEITA DA CANA-DE- -AÇÚCAR: PERSPECTIVAS FUTURAS AO CUMPRIMENTO DO PROTOCOLO AGROAMBIENTAL
}

\section{MAIKON R. DE NOVAES ${ }^{1}$, BERNARDO F. T. RUDORFF ${ }^{2}$, CLÁUDIA M. DE ALMEIDA ${ }^{3}$, DANIEL A. DE AGUIAR ${ }^{4}$}

\begin{abstract}
RESUMO: Estimada em quase 8 milhões de hectares, a área cultivada com cana no País possui $60 \%$ de sua extensão dentro do Estado de São Paulo e encontra-se distribuída de maneira heterogênea pelo seu território. Em junho de 2007, a União da Indústria de Cana-de-Açúcar (UNICA) e a SMA-SP assinaram um protocolo agroambiental para antecipar a extinção da queima da palha para 2014, em áreas com declividade inferior a $12 \%$. O objetivo deste trabalho é realizar uma análise sobre a adesão dos municípios a este protocolo frente à dinâmica da prática da queima, utilizando técnicas de análise espacial. Foram selecionadas duas regiões de acordo com o índice de Moran, e realizadas análises sobre a mudança em relação à prática da queima no período entre 2006 e 2008. Matrizes de transição foram calculadas usando um modelo estacionário baseado na cadeia de Markov. Um segundo modelo, prescritivo, foi elaborado por indicação de especialistas. Os resultados apontaram que há clusters onde a adesão ao protocolo é maior, como no entorno de Barretos e Ribeirão Preto, enquanto em outras áreas a prática da queima ainda prevalece, como nas proximidades de Ourinhos e Jaú. No entanto, as análises feitas mostraram que há forte inclinação à adesão em todas as regiões de estudo.
\end{abstract}

PALAVRAS-CHAVE: protocolo agroambiental, análise espacial, SIG.

\section{SPATIAL ANALYSIS OF THE SUGARCANE CROP BURNING REDUCTION: FUTURE PERSPECTIVES TO THE FULFILLMENT OF THE AGRI-ENVIRONMENTAL PROTOCOL}

\begin{abstract}
The estimated sugarcane cultivated area in Brazil lies around 8 million hectares, $60 \%$ of which are found within the state of São Paulo, unevenly scattered throughout its territory. In June 2007, the Sugarcane Industry Association (UNICA) and SMA-SP signed an AgrI-Environment protocol, designed to anticipate the end of straw burning in areas with slope under $12 \%$ until 2014. The objective of this study is to perform an analysis of São Paulo municipalities' compliance with this protocol, considering the dynamics of burning practices, using spatial analysis techniques. Two study areas were selected according to Moran's index, and analyses on the harvesting practices changes during the period between 2006 and 2008 were performed. Transition matrices were calculated using a stationary model based on the Markov chain. A second model, prescriptive, was elaborated based on expert counseling. The results showed that there are clusters where the compliance with the protocol is higher, close to Barretos and Ribeirão Preto municipalities, while near Ourinhos and Jaú, the practice of burning is still regularly kept. However, the analysis showed that in all study areas there is a strong trend to reduce the pre-harvest burning.
\end{abstract}

KEYWORDS: agri-environment protocol, spatial analysis, GIS.

\footnotetext{
${ }^{1}$ Geógrafo, Mestre em Sensoriamento Remoto, INPE, Analista de Geoprocessamento do IBGE, Natal - RN.

${ }^{2}$ Eng ${ }^{\underline{0}}$ Agrônomo, Doutor, Pesquisador Titular, DSR, INPE, São José dos Campos - SP.

${ }^{3}$ Arquiteta, Doutora, Pesquisadora Associada, DSR, INPE, São José dos Campos - SP.

${ }^{4}$ Geógrafo, Doutorando em Sensoriamento Remoto, DSR, INPE, São José dos Campos - SP.

Recebido pelo Conselho Editorial em: 5-3-2010

Aprovado pelo Conselho Editorial em: 4-4-2011
} 


\section{INTRODUÇÃO}

Desde 2006, o Instituto Nacional de Pesquisas Espaciais (INPE), em conjunto com a Secretaria do Meio Ambiente do Estado de São Paulo (SMA-SP), vem monitorando, por meio de imagens de sensoriamento remoto, o tipo de colheita, com e sem a prática da queima, em toda a área canavieira do Estado. A colheita manual da cana-de-açúcar requer a queima da palha para viabilizar o corte dos colmos. Atualmente, cerca de $10 \%$ da área de cana colhida no Estado de São Paulo é realizada com máquinas mais simples que requerem a queima da palha na pré-colheita. Entretanto, cresce consideravelmente, a cada ano, a área de cana colhida com máquinas sofisticadas que não requerem a queima da palha para a colheita dos colmos. Apesar de serem onerosas, requerendo um grande investimento, elas começam a ser economicamente mais vantajosas para os grandes empreendedores do que a colheita manual.

A prática da queima da palha da cana, adotada corriqueiramente no Estado de São Paulo, gera notáveis impactos ambientais, decorrentes da emissão de gases poluentes nocivos à qualidade de vida e à saúde da população que reside nas áreas de cultivo de cana ou no seu entorno (ROSEIRO \& TAKAYANAGUI, 2004). Todavia, diante da relevante importância da atividade sucroalcooleira para a economia e geração de empregos, renda, divisas e tributos, aliadas às medidas de responsabilidade diante das mudanças climáticas globais, com o fim de evitar o agravamento das condições ambientais desfavoráveis à qualidade de vida, foi assinado um protocolo de cooperação entre o governo e o setor sucroalcooleiro, visando a consolidar o desenvolvimento sustentável da indústria da cana-de-açúcar no Estado de São Paulo.

Tal protocolo objetiva, entre outras diretivas, antecipar, nos terrenos com declividade até $12 \%$, o prazo final para a eliminação da queimada da cana-de-açúcar ${ }^{1}$ de 2021 para 2014. Para terrenos com declividade superior a 12\%, considerados não mecanizáveis, o prazo final passa de 2031 para 2017. Em contrapartida, aqueles produtores agrícolas e indústrias que atenderem ao protocolo de cooperação obtêm um Certificado de Conformidade Agroambiental, que confere a eles algumas vantagens potencialmente importantes nos procedimentos de certificação de seus produtos para exportação.

Diante da hipótese de que haja regiões heterogêneas no tocante ao modo de colheita, este trabalho tem por objetivo identificar áreas onde existe maior concentração de prática de queima nas lavouras canavieiras, bem como áreas mais aderentes ao protocolo agroambiental, no período entre os anos de 2006 e 2008. Em seguida, a partir da observação deste período, é também objetivo deste trabalho apresentar tendências de adesão futura para estas regiões até o ano-limite, estabelecido no protocolo, através de um modelo estacionário baseado na cadeia de Markov, e de um segundo modelo, de caráter prescritivo, elaborado por especialistas na área.

\section{MATERIAL E MÉTODOS}

\section{Área de estudo}

A área de estudo compreende, inicialmente, toda a extensão territorial do Estado de São Paulo (Figura 1), uma vez que o protocolo ambiental em prol da extinção da prática da queima na colheita da cana-de-açúcar, principal justificativa do presente trabalho, é válido para este Estado.

São Paulo localiza-se aproximadamente entre as latitudes de $19^{\circ} 05^{\prime} \mathrm{S}$ e $25^{\circ} 00^{\prime} \mathrm{S}$ e as longitudes de $44^{\circ} 00^{\prime} \mathrm{W}$ e $53^{\circ} 05^{\prime} \mathrm{W}$ e está inserido na região Sudeste do Brasil, com uma área total de $248.209 \mathrm{~km}^{2}$, contendo 645 municípios e um total de população estimado, em 2007, em torno de 39.827.570 habitantes, ou seja, concentra mais de $20 \%$ de toda a população do País (IBGE, 2009). Além de ser o Estado responsável por grande parte do PIB brasileiro, este concentra, atualmente, cerca de $60 \%$ do total de área cultivada de cana-de-açúcar no País, ocupando aproximadamente $19 \%$ do território do Estado.

\footnotetext{
${ }^{1}$ Os prazos originais encontram-se na Lei $\mathrm{N}^{\circ} 11.241$, de 19 de setembro de 2002.
} 


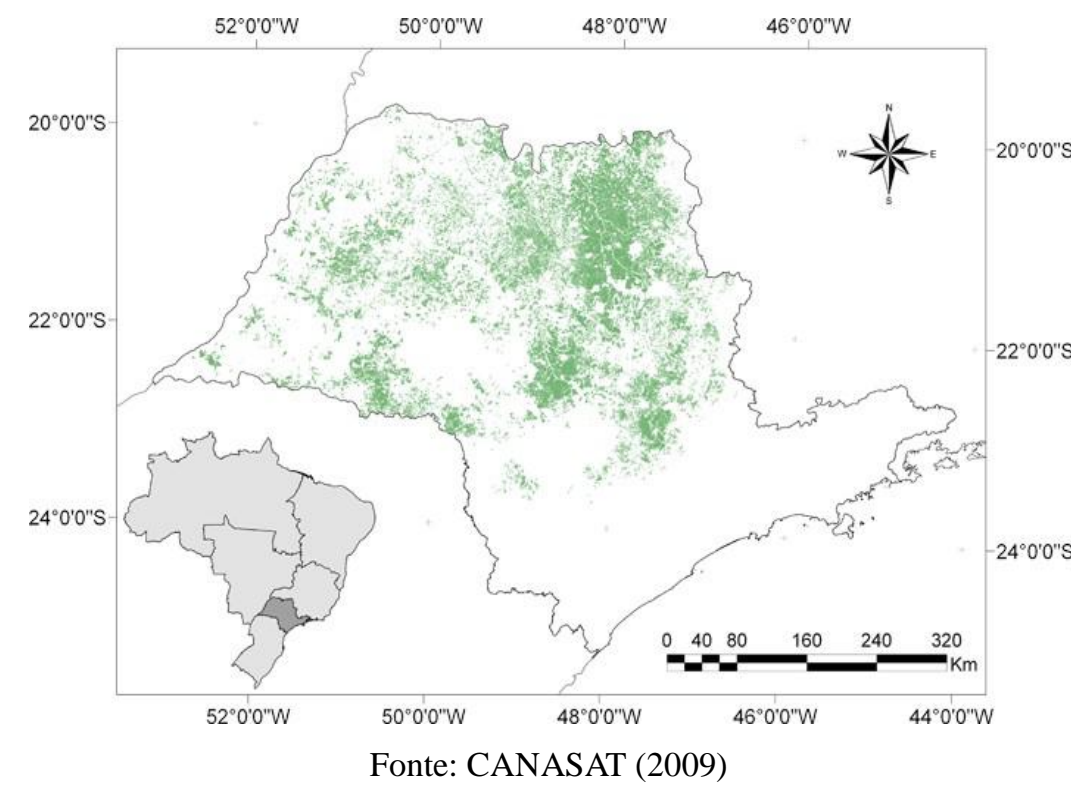

FIGURA 1. Localização das áreas canavieiras (em verde) no Estado de São Paulo, em 2008. Location of sugarcane crops (in green) in the state of São Paulo in 2008.

\section{Dados do modo de colheita oriundos de monitoramento por satélites}

O monitoramento da prática da queima é realizado a partir da obtenção da distribuição espacial da colheita do ano imediatamente anterior, aliado às imagens orbitais selecionadas de acordo com o calendário agrícola da cultura da cana. Após a colheita da cana, as lavouras colhidas com e sem a prática da queima apresentam uma resposta espectral bem distinta e são facilmente identificadas nas imagens de sensoriamento remoto, mesmo em imagens adquiridas algumas semanas após o evento da colheita (AGUIAR et al., 2009).

Atualmente, a identificação das áreas colhidas com e sem queima da palha é realizada em imagens Landsat5 TM, adquiridas continuamente ao longo da safra, de abril a novembro, utilizando técnicas de interpretação visual na tela do computador. $\mathrm{O}$ mapeamento da colheita é representado por dados, devidamente classificados, do tipo matricial, com resolução espacial de $30 \mathrm{~m}$. Cada porção do terreno classificado possui informações como área, perímetro e sua respectiva classificação quanto ao modo de colheita. As classes são: cana crua (colheita sem uso do fogo), cana queima (com uso do fogo) ou cana bisada (não colhida). Os dados disponíveis para o modo de colheita correspondem aos anos-safra de 2006, 2007 e 2008.

\section{Construção do índice de colheita}

$\mathrm{Na}$ tentativa inicial de reconhecer um comportamento espacial regionalizado, construiu-se uma variável com base nos valores de cana queima e cana crua colhida por unidade de área. $\mathrm{O}$ índice de colheita indica a proporção do tipo de colheita para cada unidade de área, em que valores positivos e negativos indicam maior proporção de $C c$ e $C q$, respectivamente, oscilando entre -1 e 1 .

$$
I C=\frac{\% C c-\% C q}{100}
$$

Com a finalidade de garantir um resultado fiel ao conteúdo dos dados na sua resolução original, foi gerada uma grade de células vetoriais com resolução de 2.000 x 2.000 m, abrangendo todo o limite do Estado de São Paulo. Em seguida, com o auxílio da plataforma TerraView 3.3.0, por meio da operação geográfica "Atribuir dado por localização", foi possível agregar atributos de área das respectivas classes de colheita $(C c$ ou $C q)$ através da interseção de cada área classificada pelas células geradas. Feita esta atribuição para as áreas, foi calculado o índice de colheita (IC) para 
cada célula da grade, obtendo, desta forma, uma espécie de "proporção de queima" para cada célula de 400 ha. A transformação é ilustrada na Figura 2.

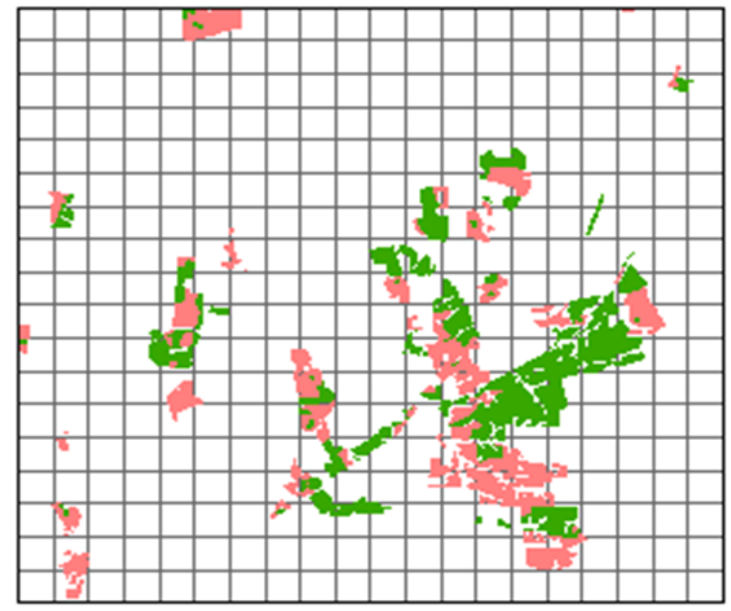

Mapa de Colheita

Cana Colhida

cana-crua

cana-queima
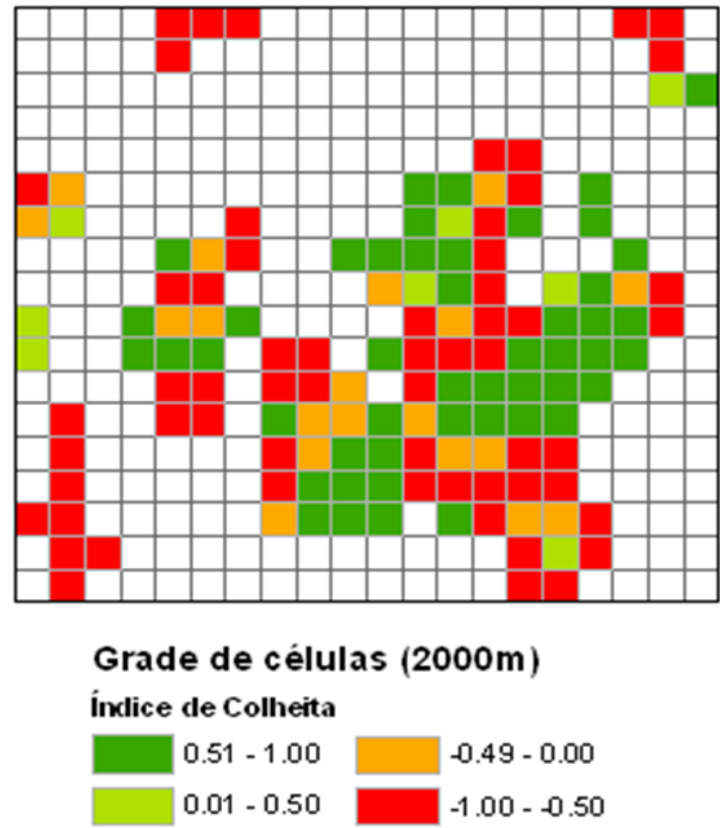

FIGURA 2. Procedimento de geração do índice de colheita para a grade de células com resolução de $2.000 \mathrm{~m}$. Procedure to generate harvest indices for grid cells with a spatial resolution of $2,000 \mathrm{~m} \times 2,000 \mathrm{~m}$.

\section{Análise espacial na identificação de agrupamentos e subsídios à compreensão da prática da colheita da cana}

No campo da geoinformação, entende-se por regionalização uma operação que realiza o agrupamento de objetos-área em regiões homogêneas e contíguas no espaço. A fim de alcançar tal objetivo, busca-se uma nova repartição do espaço de estudo em um número menor de objetos, resultando em novas áreas ou regiões com dimensões geográficas mais abrangentes e mais homogêneas. Pesquisas recentes evidenciaram um comportamento regionalizado das plantações e do manejo da colheita da cana-de-açúcar para dados agregados por municípios (AGUIAR et al., 2007; NOVAES et al., 2009).

Em uma análise exploratória espacial, é fundamental verificar a caracterização da dependência espacial, identificando como atributos de um fenômeno estudado estão correlacionados no espaço. Um índice que expressa autocorrelação espacial, considerando apenas o primeiro vizinho, é o índice global de Moran, que indica a existência ou não de áreas agrupadas (clusters), cujos atributos se apresentam de maneira semelhante no espaço. Para o cálculo deste índice, é indispensável a hipótese de que os dados sejam estacionários de primeira e segunda ordems (CÂMARA et al., 2004). Uma das formas de avaliar se o dado é ou não estacionário, além de olhar atentamente o mapa em busca de padrões, é utilizar a função de autocorrelação espacial considerando vizinhos de diversas ordens. $O$ índice expressa a autocorrelação de atributos entre pares em função de suas respectivas distâncias. Quando o dado não é estacionário, a função decresce muito lentamente. O índice global de Moran $I$ é expresso de acordo com a fórmula a seguir: 


$$
I=\frac{\sum_{i=1}^{n} \sum_{j=1}^{n} w_{i j}\left(z_{i}-\bar{z}\right)\left(z_{j}-\bar{z}\right)}{\sum_{i=1}^{n}\left(z_{i}-\bar{z}\right)^{2}}
$$

em que,

n - número de áreas;

$\mathrm{z}_{\mathrm{i}}$ - valor do atributo considerado na área $\mathrm{i}$;

$\bar{z}$ - valor médio do atributo na região de estudo, e

$\mathrm{W}_{\mathrm{ij}}$ - pesos atribuídos conforme a conexão entre as áreas i e j.

O índice de Moran testa a hipótese nula de independência espacial. Caso a hipótese se confirme, o valor deste índice tende a 0 . Valores positivos (em direção a +1 ) indicam uma correlação direta, e valores negativos (em direção a -1), correlação inversa; ambas, entretanto, apontam para a dependência espacial. Além de calcular o índice, é necessário estimar a significância do mesmo. Segundo CÂMARA et al. (2004), uma forma usual de realizar esse teste é associar a distribuição estatística como normal ou realizar um teste de pseudossignificância.

Uma maneira interessante de visualizar os dados de dependência espacial é através do Diagrama de Espalhamento de Moran (CÂMARA et al., 2004). Este consiste em comparar, através de um gráfico bidimensional, os valores normalizados $(z)$ com a média dos seus vizinhos ( $w z$.). O gráfico pode ser interpretado dividindo-o em quatro quadrantes, conforme exemplos apresentados no canto inferior direito da Figura 3, e o índice de Moran equivale ao coeficiente de regressão linear que indica a inclinação angular da reta de regressão $(\alpha)$ de $w z$ em $z$. Neste gráfico bidimensional, pode-se visualizar a quantidade de entidades que se encontram direta e inversamente correlacionadas espacialmente com seus vizinhos.

Segundo CÂMARA et al. (2004), os quadrantes podem ser interpretados como:

- Q1 ou quadrante superior direito (altos valores normalizados correlacionados com alta média dos valores vizinhos - high-high) e Q2 ou quadrante inferior esquerdo (baixos valores normalizados correlacionados com baixa média dos valores vizinhos - low-low) indicam pontos de associação espacial positiva, no sentido de que uma localização possui vizinhos com valores semelhantes.

- Q3 ou quadrante inferior direito (altos valores normalizados com baixa média dos valores vizinhos - high-low) e Q4 ou quadrante superior esquerdo (baixos valores normalizados com alta média dos valores vizinhos - low-high) indicam pontos de associação espacial negativa, no sentido de que uma localização possui vizinhos com valores distintos. Estes, dependendo do fenômeno, podem indicar aleatoriedade ou áreas suscetíveis à transição de valores baixos para altos, ou viceversa.

Em casos em que é necessário analisar diversas áreas, é muito provável que esteja contido no conjunto de dados mais de um regime de associação espacial. Desta maneira, os indicadores de autocorrelação global, como o índice de Moran, irão examinar a região de estudo em sua totalidade, mas irão restringir análises em busca de padrões mais locais. Para superar isso, é necessário utilizar indicadores de associação espacial que possam ajustar-se às diferentes localizações de uma variável distribuída espacialmente.

\footnotetext{
${ }^{2}$ Para mais detalhes sobre o teste de pseudossignificância, consultar CÂMARA et al. (2004) e BAILEY \& GATRELL (1996).

${ }^{3}$ Valores normalizados são aqueles associados ao atributo estudado, subtraídos de sua média e divididos pelo desvio-padrão.
} 
Segundo ANSELIN (1995), o Indicador de Associação Espacial Local ou LISA (Local Indicator of Spatial Association) pode evidenciar agrupamentos em que ocorram diferentes regimes espaciais, pois se obtém também um indicador correspondente à subárea composta pelos vizinhos, e é calculada, para cada área, sua significância estatística.

Neste trabalho, a matriz de proximidade espacial foi extraída a partir do índice de colheita e foram realizados os testes globais de Moran, assim como um mapa representativo dos quatro quadrantes de Moran, com um intervalo de confiança de 95\% (LISAMAP), para aquelas células que continham áreas de lavoura. Todos os processamentos foram realizados no programa SPRING 4.3.3 ${ }^{4}$, no qual foram também gerados os dados do Projeto CANASAT, eliminando a necessidade de transferência de dados entre SIGs. Foram selecionadas duas regiões para a etapa seguinte, a qual consiste no cálculo dos percentuais de mudanças. Essa seleção foi realizada com base na detecção de clusters de células representadas pelos quadrantes 1 e 2, high-high (HH) e low-low (LL), respectivamente. A primeira região $(\mathrm{HH})$ é composta pelos municípios de Barrinha, Dumont, Jaboticabal, Pradópolis, Ribeirão Preto e Sertãozinho. A segunda região (LL) abrange os municípios de Bariri, Barra Bonita, Bocaina, Boraceia, Dois Córregos, Igaraçu do Tietê, Itaju, Itapuí, Jaú, Macatuba, Mineiros do Tietê e Pederneiras.

\section{Cálculo de matrizes de transição e geração de cenários estacionário e prescritivo}

Neste trabalho, o modelo adotado para a quantificação de mudanças de uso e cobertura da terra é baseado na cadeia de Markov. Este modelo descreve certo tipo de processo, que se move em uma sequência de passos e através de um conjunto de estados ${ }^{5}$. Supõe-se que a probabilidade de um conjunto particular de saídas depende unicamente da distribuição atual entre os estados e suas probabilidades de transição. Além do mais, o modelo considera que a matriz de transição relativa ao fenômeno estudado é estacionária, o que nem sempre ocorre nos processos ambientais dinâmicos.

As matrizes de transição para as duas áreas de estudo foram geradas no programa IDRISI Andes ${ }^{6}$ por tabulação cruzada, para o período de 2006 a 2008, e transferidas para o programa Excel 2003, a fim de se projetarem as áreas de cana bisada $(C b)$, cana queima $(C q)$, cana crua $(C c)$ e demais áreas não cultivadas com cana para os anos de 2010, 2012 e 2014, resultando em cenários futuros estacionários. Outros cenários correspondentes ao mesmo período foram gerados a partir de um segundo modelo, baseado no conhecimento e indicações de especialistas na área da dinâmica de colheita canavieira. Neste último, foram alterados os percentuais de transição de classes, devido ao fato de alguns fenômenos terem sido desconsiderados, como o aumento anômalo da cana bisada e a tendência dos produtores a se ajustarem frente à redução drástica da prática da queima na pré-colheita. Uma comparação destes cenários é apresentada nos resultados desta pesquisa.

\section{RESULTADOS E DISCUSSÃO}

\section{Análise espacial do uso do fogo nas lavouras canavieiras}

Os índices de autocorrelação global de Moran foram de 0,689; 0,634 e 0,617, para os anos de 2006, 2007 e 2008, respectivamente. Percebe-se, através dos índices e do próprio mapa, que a concentração espacial das áreas de colheita com e sem queima vem diminuindo no Estado de São Paulo. Provavelmente, isto se deve por conta das recentes mudanças e investimentos na mecanização em áreas de expansão. De acordo com a Figura 3, duas regiões apresentam um quadro conservador perante a mecanização até o ano de 2008: a de Ourinhos e entorno, localizada na divisa do Estado do Paraná, e a região no entorno do município de Jaú, tradicional no cultivo de cana. Áreas de crescente expansão da cultura canavieira, como a região de Ribeirão Preto e entorno, mostram-se aderentes ao processo de mecanização até este período. Regiões tradicionais neste cultivo, que têm forte adesão à extinção da queima, são Barretos e Ribeirão Preto, e suas proximidades.

\footnotetext{
${ }^{4}$ O SPRING é um SIG de domínio público desenvolvido pelo INPE e disponível em http://www.dpi.inpe.br/spring/.

${ }^{5}$ Para mais detalhes sobre a Cadeia de Markov, consultar BAKER (1989).

${ }^{6}$ O IDRISI Andes é um SIG desenvolvido pela Clark University, EUA (www.clarklabs.org).
} 

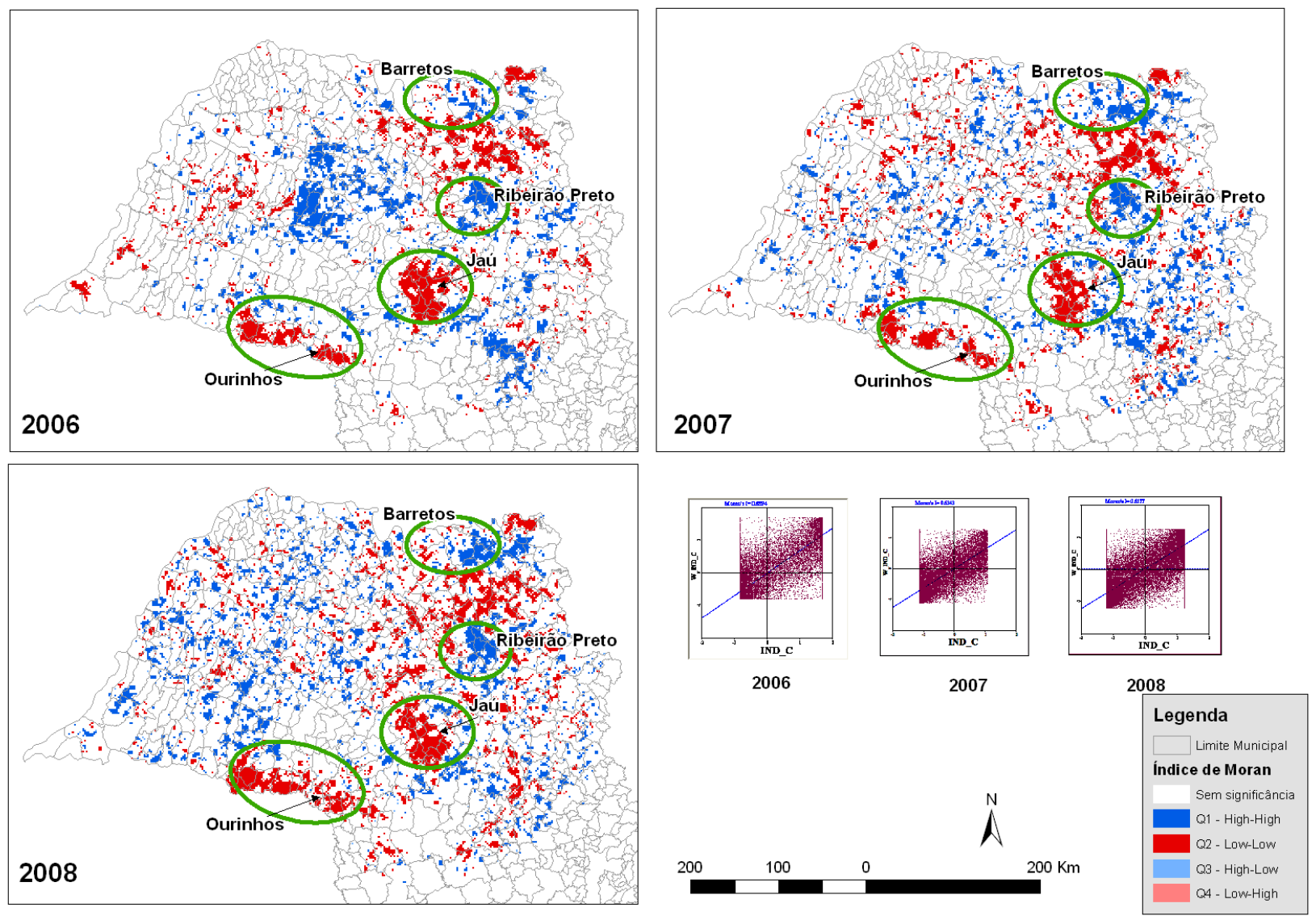

FIGURA 3. Autocorrelação global para o índice de colheita das células de $2 \mathrm{x} 2 \mathrm{~km}$ e mapa de clusters derivado da análise pela função LISAMAP, para os anos-safra de 2006, 2007 e 2008. Global autocorrelation for the harvest index ( $2 \times 2 \mathbf{~ k m}$ cells) and cluster analysis with the LISAMAP function for the crop years 2006, 2007, and 2008.

As regiões selecionadas demonstram relações espaciais quanto à prática da queima bem distintas entre si. Na Figura 4, é nítida esta distinção em 2008, comprovando que o uso do índice de Moran destacou as áreas de agrupamentos de forma adequada. 

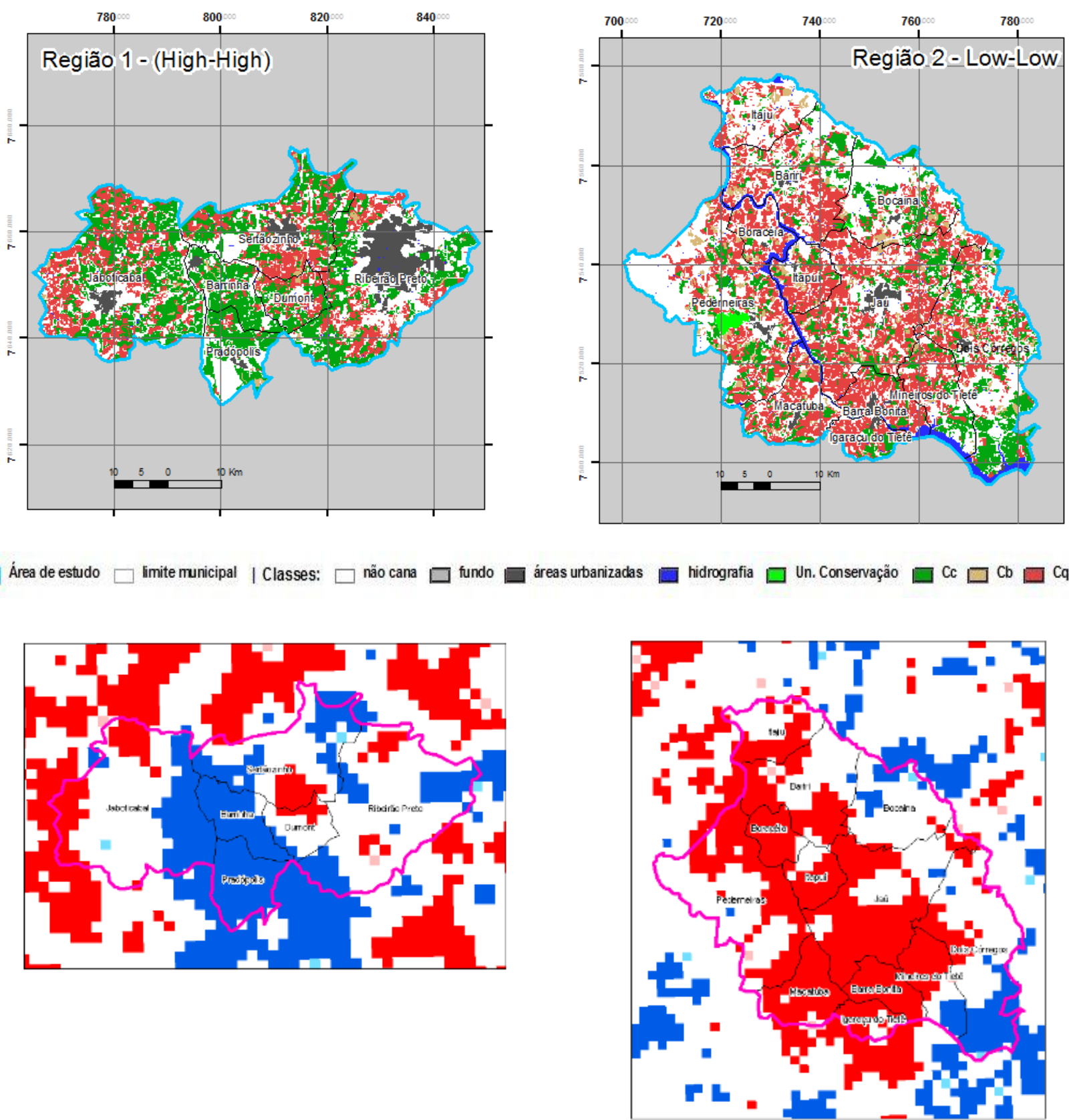

Índice de Moran $\square$ não-significante $\square$ Q1-High-High $\square$ Q2-Low-Low $\square$ Q3-High-Low $\square$ Q4-Low-High

FIGURA 4. Resultado da seleção de áreas segundo análise de autocorrelação espacial local. Selection of areas according to the local spatial autocorrelation analysis.

Análise das mudanças nas práticas de colheita da cana-de-açúcar e na expansão da cultura canavieira através das matrizes de transição

A região 1, contendo agrupamentos cujos índices de colheita são, em sua maioria, altos $(\mathrm{HH})$, possui uma extensa área e vem incorporando novas tecnologias de mecanização, vindo ao encontro das diretrizes do protocolo ambiental. Mesmo em número bem menor, destaca-se aqui um percentual de áreas $(50,21 \%)$ que mantiveram o uso da queima no período observado (Tabela 1). Por outro lado, mais de 1/3 (34,62\%) da área queimada em 2006 foi colhida sem o uso do fogo em 2008. 
TABELA 1. Região 1: Matriz de transição. a) valores em ha; b) percentual estacionário; c) percentual prescritivo. Region 1: Transition matrix. a) Values in ha. b) stationary percentage; c) prescriptive percentage.

\begin{tabular}{cccrrr}
\hline a) $2006 / 2008$ & Não cana & $\mathrm{Cb}$ & \multicolumn{1}{c}{$\mathrm{Cq}$} & $\mathrm{Cc}$ & Total \\
\hline Não cana & 46.527 & 544 & 8.953 & 12.474 & 68.497 \\
\hline $\mathrm{Cb}$ & 444 & 14 & 721 & 1.490 & 2.669 \\
$\mathrm{Cq}$ & 8.964 & 1.510 & 34.649 & 23.892 & 69.016 \\
$\mathrm{Cc}$ & 10.305 & 1.235 & 8.398 & 39.302 & 59.240 \\
\hline Total & 66.240 & 3.302 & 52.721 & 77.159 & 439.178 \\
\hline b) 2006/2008 & Não cana & $\mathrm{Cb}$ & $\mathrm{Cq}$ & $\mathrm{Cc}$ & Total \\
\hline Não cana & $67,93 \%$ & $0,79 \%$ & $13,07 \%$ & $18,21 \%$ & $100 \%$ \\
$\mathrm{Cb}$ & $16,64 \%$ & $0,51 \%$ & $27,03 \%$ & $55,82 \%$ & $100 \%$ \\
$\mathrm{Cq}$ & $12,99 \%$ & $2,19 \%$ & $50,21 \%$ & $34,62 \%$ & $100 \%$ \\
$\mathrm{Cc}$ & $17,40 \%$ & $2,08 \%$ & $14,18 \%$ & $66,34 \%$ & $100 \%$ \\
\hline c) $2006 / 2008$ & Não cana & $\mathrm{Cb}$ & $\mathrm{Cq}$ & $\mathrm{Cc}$ & Total \\
\hline Não cana & $67,93 \%$ & $0,79 \%$ & $7,00 \%$ & $24,28 \%$ & $100 \%$ \\
$\mathrm{Cb}$ & $16,64 \%$ & $0,51 \%$ & $27,03 \%$ & $55,82 \%$ & $100 \%$ \\
$\mathrm{Cq}$ & $12,99 \%$ & $2,19 \%$ & $25,00 \%$ & $59,82 \%$ & $100 \%$ \\
\hline $\mathrm{Cc}$ & $17,40 \%$ & $2,08 \%$ & $8,00 \%$ & $72,52 \%$ & $100 \%$ \\
\hline
\end{tabular}

Percebe-se que, nesta região de estudo, há uma quantidade de áreas onde a mecanização se encontra bastante consolidada, pois $66,34 \%$ das áreas de cana crua permaneceram no mesmo estado em 2008. 14,18\% de lavouras que colhiam sem queima, usaram o recurso do fogo em 2008, e $17,40 \%$ delas estavam em reforma. No primeiro caso, não significa necessariamente que o produtor tenha deixado de utilizar a colheita mecânica. $\mathrm{Na}$ verdade, como a prática da queima ainda é permitida, alguns produtores queimam a palha da cana para tornar a colheita mais ágil.

A região de estudo 2, relativa ao município de Jaú e entorno, caracteriza-se por ser mais tradicional no cultivo da cana-de-açúcar, e com métodos de colheita mais conservadores. Analisando a Tabela 2, percebe-se que, do total de área colhida com queima em 2006, 54,35\% permanecem com o mesmo tipo de colheita.

TABELA 2. Região 2: Matriz de transição. a) valores em ha; b) percentual estacionário; c) percentual prescritivo. Region 2: Transition matrix. a) values in ha; b) stationary percentage; c) prescriptive percentage.

\begin{tabular}{ccccrr}
\hline a) $2006 / 2008$ & Não cana & $\mathrm{Cb}$ & $\mathrm{Cq}$ & $\mathrm{Cc}$ & \multicolumn{1}{c}{ Total } \\
\hline Não cana & 133.458 & 5.377 & 30.212 & 12.327 & 181.375 \\
$\mathrm{Cb}$ & 644 & 1.017 & 2.711 & 1.721 & 6.093 \\
$\mathrm{Cq}$ & 25.397 & 14.207 & 88.044 & 34.354 & 162.002 \\
$\mathrm{Cc}$ & 4.575 & 1.609 & 8.915 & 13.828 & 28.926 \\
\hline Total & 164.074 & 22.210 & 129.882 & 62.230 & 695.012 \\
\hline b) 2006/2008 & Não cana & $\mathrm{Cb}$ & $\mathrm{Cq}$ & $\mathrm{Cc}$ & Total \\
\hline Não cana & $73,58 \%$ & $2,96 \%$ & $16,66 \%$ & $6,80 \%$ & $100 \%$ \\
$\mathrm{Cb}$ & $10,56 \%$ & $16,69 \%$ & $44,50 \%$ & $28,24 \%$ & $100 \%$ \\
$\mathrm{Cq}$ & $15,68 \%$ & $8,77 \%$ & $54,35 \%$ & $21,21 \%$ & $100 \%$ \\
$\mathrm{Cc}$ & $15,82 \%$ & $5,56 \%$ & $30,82 \%$ & $47,80 \%$ & $100 \%$ \\
\hline c) 2006/2008 & Não cana & $\mathrm{Cb}$ & $\mathrm{Cq}$ & $\mathrm{Cc}$ & Total \\
\hline Não cana & $73,58 \%$ & $0,10 \%$ & $10,00 \%$ & $16,32 \%$ & $100 \%$ \\
\hline $\mathrm{Cb}$ & $10,56 \%$ & $2,00 \%$ & $14,00 \%$ & $73,44 \%$ & $100 \%$ \\
\hline $\mathrm{Cq}$ & $15,68 \%$ & $1,00 \%$ & $23,00 \%$ & $60,32 \%$ & $100 \%$ \\
\hline $\mathrm{Cc}$ & $15,82 \%$ & $1,00 \%$ & $8,00 \%$ & $75,18 \%$ & $100 \%$ \\
\hline
\end{tabular}


Por outro lado, vê-se uma postura convergindo com a proposta do protocolo ambiental, refletida pela mudança em $21 \%$ das áreas de queima para áreas sem queima. Todavia, as áreas de cana crua ainda representam $29 \%$ da área total de cana na região. Das novas áreas de cana, ainda há certa resistência frente à mecanização, pois em $63 \%$ destas áreas foi utilizada a queima, enquanto apenas $26 \%$ das áreas novas aderiram ao protocolo.

Um fenômeno observado nesta região é o percentual bastante elevado de cana não colhida. Ao todo, foram 22.210 ha de cana bisada. Tal fenômeno pode ser atribuído a um desequilíbrio entre a maior disponibilidade de matéria-prima e a menor capacidade de produção de álcool e açúcar prevista pelas unidades de produção. Outro ponto a ser observado é o percentual de quase $16 \%$ (25.397 ha) de área de cana queima em 2006, que passou a não constar em 2008. Existe a possibilidade de que estejam em reforma ou de que parte delas tenha cedido lugar a outras culturas.

\section{Cenários futuros e indicativos de aderência ao protocolo agroambiental}

Com base nas matrizes de transição estacionária e prescritiva, foram calculadas quantidades de área em cada classe, para os anos de 2010, 2012 e 2014, conforme apresentado na Figura 5. De acordo com estes gráficos, a prática da queima sofrerá um decréscimo nos anos seguintes. Porém, em todas as regiões, é previsto o aumento da colheita mecanizada em relação ao ano de 2006 . As taxas mais significativas deste crescimento, segundo o modelo, são para a região 1 , onde se localiza o município de Ribeirão Preto.

\section{Modelo estacionário}

Região 1

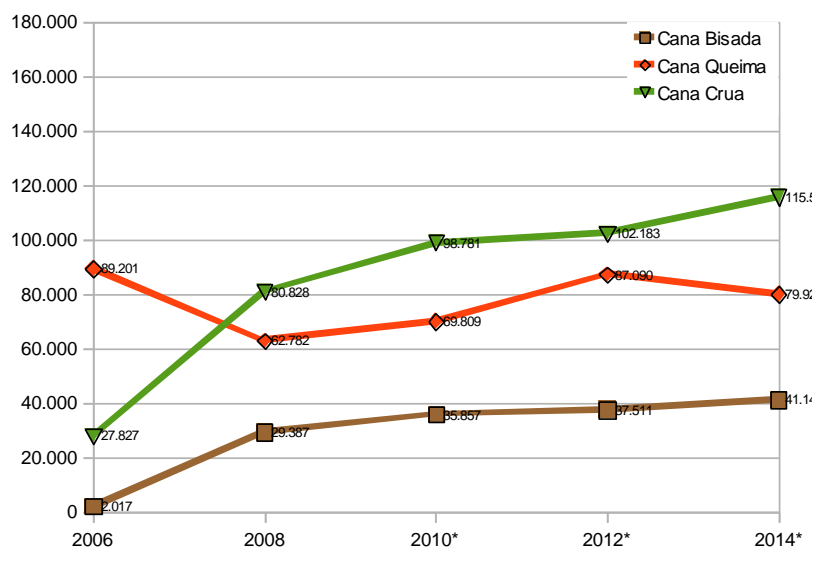

Região 2

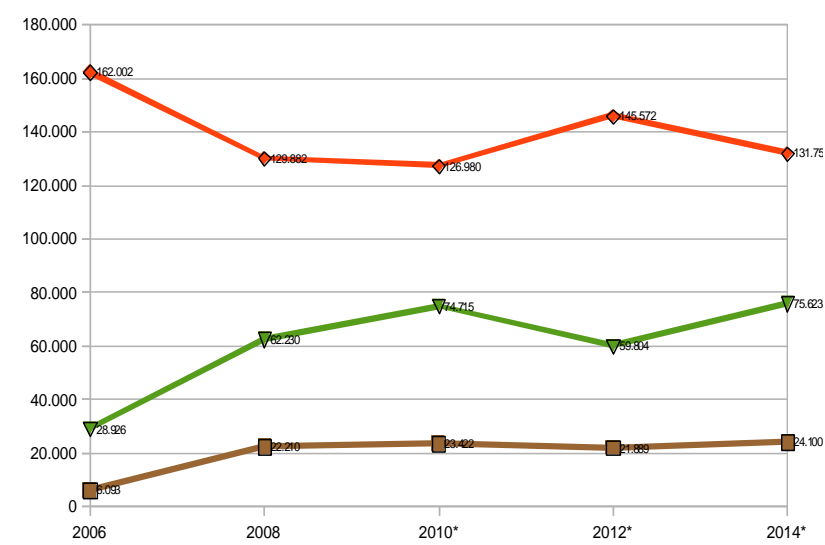

Modelo prescritivo

Região 1

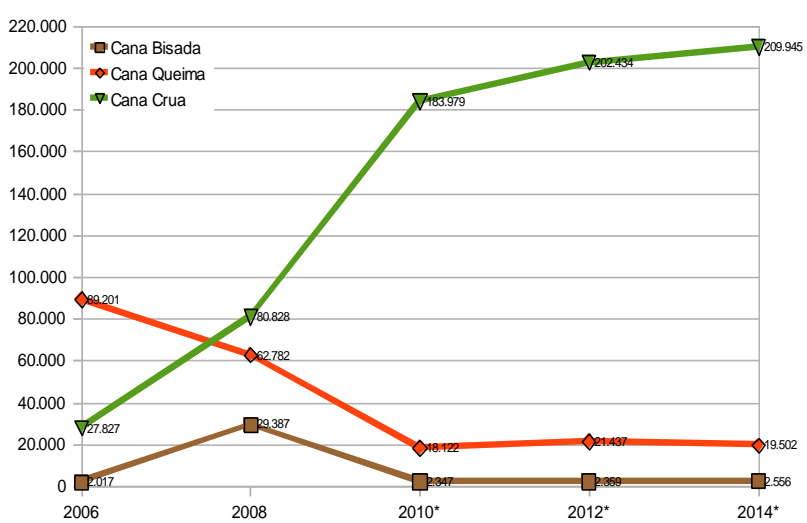

Região 2

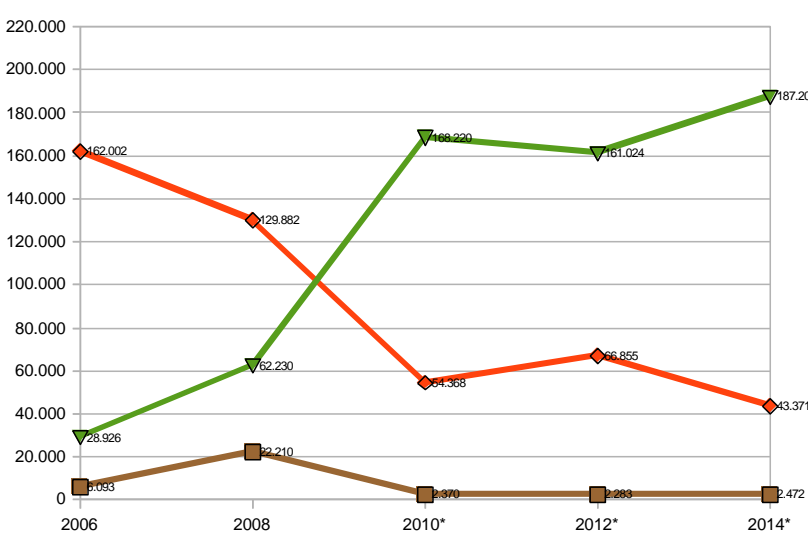

FIGURA 5. Cenários futuros para as classes de colheita da cana-de-açúcar em hectares, segundo os modelos estacionário e prescritivo. Future scenarios for the sugarcane harvest classes in hectares according to the stationary and the prescriptive models. 
Contudo, especialistas acreditam que estes cenários simulados a partir de um modelo estacionário não viriam a ocorrer, de acordo com as perspectivas futuras e tendência geral à adesão ao protocolo por parte dos produtores de cana-de-açúcar. Para eles, o aumento da cana bisada nas regiões 1 e 2, como prevê este modelo, é um acontecimento irreal. Além disso, existe uma inclinação à mecanização para todos estes municípios, por motivos, principalmente, econômicos.

Segundo este modelo, as taxas de crescimento da mecanização das lavouras canavieiras e de decréscimo do uso do fogo seriam muito maiores do que as estimadas pelo modelo estacionário, enquanto a ocorrência da cana bisada permaneceria, conforme esperado, para os anos que seguem.

Apesar de ambos os modelos apresentarem taxas distintas de decréscimo da prática da queima nas lavouras, para as regiões de estudo, nenhuma delas em sua íntegra teve uma adesão de $100 \%$ em cenário projetado para o ano de 2014. A adesão supõe que o percentual de cana-de-açúcar colhida é integralmente obtido sem o uso do fogo. A Figura 6 ilustra os gráficos comparativos, relativos à estimativa de adesão das duas regiões de estudo, segundo os dois modelos.

Enquanto o modelo estacionário prevê que nenhuma região, como um todo, irá atingir acima de $60 \%$ de adesão, o modelo prescritivo indica que, salvo suas diferenças atuais, este percentual apresenta-se mais otimista. De qualquer maneira, se este indicador for tratado para cada município isoladamente, é provável que muitos consigam cumprir a meta estabelecida. O modelo estacionário aponta que a região 1 alcance quase $60 \%$ de adesão, e uma situação bastante conservadora para a região 2 , cerca de $37 \%$. Por outro lado, o modelo prescritivo indica maior adesão destas regiões que, apesar de não cumprirem totalmente o protocolo até o ano estabelecido, atingiriam um percentual superior a $80 \%$ de adesão.

Grau de Aderência ao Protocolo Agroambiental
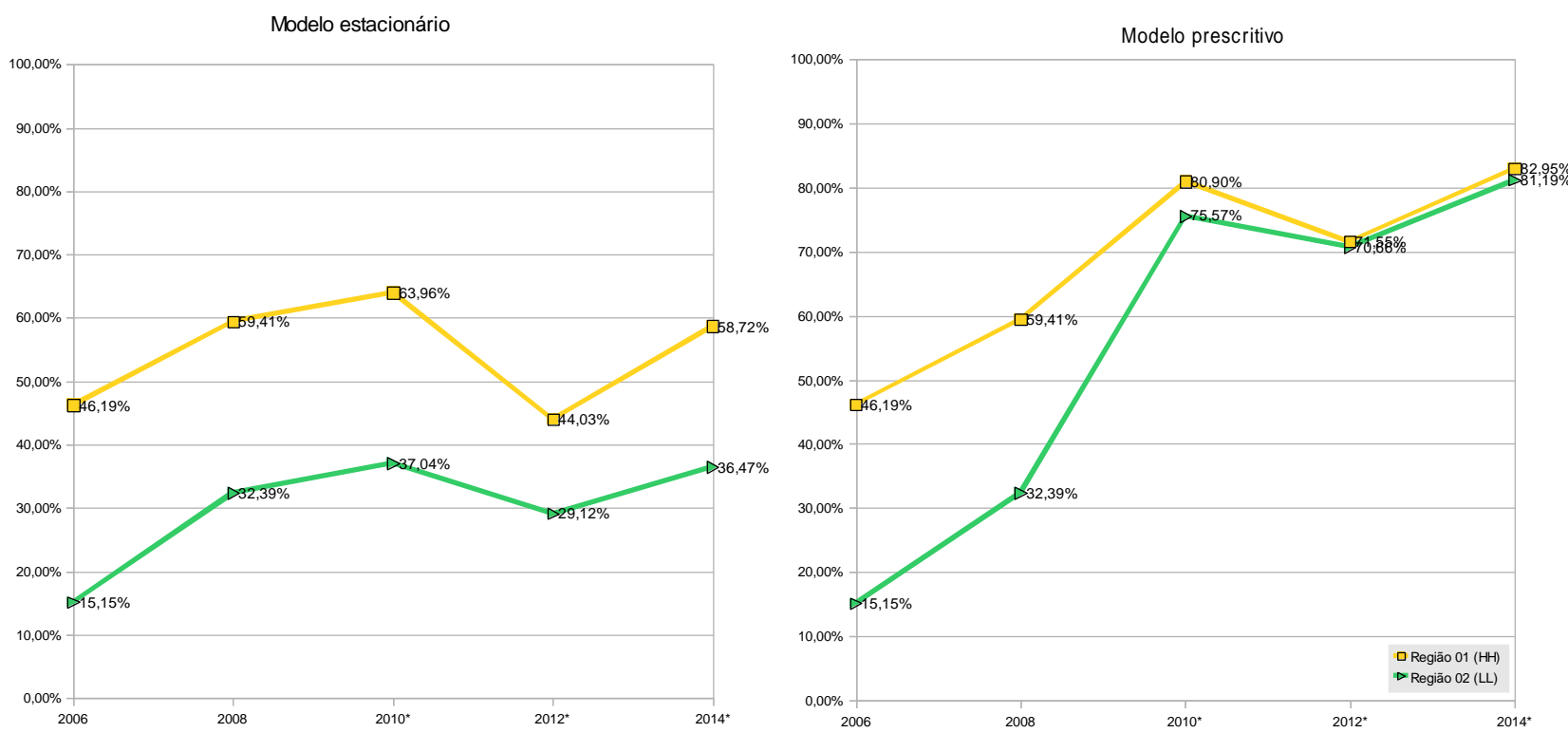

FIGURA 6. Comparação entre projeções futuras de adesão ao protocolo agroambiental para ambas as áreas de estudo. Comparison of future projections of compliance with the agrienvironmental protocol for both study areas.

\section{Avaliação do modelo estacionário e do modelo prescritivo}

O modelo estacionário, baseado na cadeia de Markov, reproduziu para o futuro as mesmas taxas que ocorreram no passado. Convém lembrar que o período disponível de dados observados é curto e foi marcado por intensas especulações e oscilações do etanol e do açúcar nos mercados nacional e internacional. Este fato, direta e indiretamente, afetou a produção e toda a dinâmica da cana-de-açúcar no Brasil, assim como seu respectivo planejamento. Exemplo disto é o alto número de áreas de cana não colhida (bisada), observado em maior grau na área de estudo correspondente ao entorno de Jaú (Região 2). Fenômenos como este, que ocorreram neste intervalo de tempo, não tendem a ocorrer com frequência, pois acarretam grandes prejuízos para o produtor. 
O modelo estacionário, no entanto, não prevê acontecimentos aleatórios, pois trata os sucessivos passos de tempo sem considerar rupturas e oscilações bruscas nas tendências de mudanças observadas. Modelos que incorporem variações econômicas de mercado, através de equações matemáticas que alterem as respectivas matrizes de transição, permitiriam contemplar outras propostas de cenários futuros, os quais poderiam ser comparados com o modelo prescritivo, esperado por especialistas. Assim, haveria a possibilidade de compor um quadro mais amplo e seguro, beneficiando os tomadores de decisão nas atividades de planejamento.

\section{CONCLUSÕES}

O método de análise espacial permitiu identificar agrupamentos de áreas com diferentes tipos de colheita. Deste modo, pode-se acompanhar a espacialização das áreas de queima e não queima da palha da cana em cada ano-safra, a fim de verificar como o fenômeno se desenvolve no espaço.

Do ponto de vista das simulações de cenários futuros, o modelo estacionário (cadeia de Markov) não pode concluir apontamentos seguros sobre as prováveis áreas que aderirão à extinção da queima até 2014, visto que a série temporal de observações disponível é insuficiente. O modelo prescritivo, por sua vez, indica que, ao final do prazo estipulado pelo protocolo ambiental, as regiões de estudo atenderiam em torno de $80 \%$ à extinção da queima na colheita da cana.

A concepção de cenários distintos, através dos dois modelos expostos, pode ser utilizada por tomadores de decisão para fornecer indícios de tendência do comportamento das regiões de estudo em questão. De qualquer modo, ambos os modelos são incapazes de prever, com alto nível de segurança, cenários de uma cultura dinâmica como a da cana-de-açúcar.

\section{REFERÊNCIAS}

AGUIAR, D.A.; RUDORFF, B.F.T.; ADAMI, M.; SHIMABUKURO, Y.E. Imagens de sensoriamento remoto no monitoramento da colheita da cana-de-açúcar. Engenharia Agrícola, Jaboticabal, v.29, n.3, p.440-451, 2009.

AGUIAR, D.A.; WAGNER F.S.; FEITOSA, F.F.; GONÇALVES, F.G.; RIZZI, R.; RUDORFF, B.F.T. Análise espacial da colheita da cana-de-açúcar no Estado de São Paulo: a influência da precipitação. In: SBSR, 13., 2007, Florianópolis. Anais... SJC: INPE, 2007, p.2.231-2.238.

ANSELIN, L. Local indicators of spatial association - LISA. Geographical Analysis, New York, v.27, n.2, p.93-115, abril 1995.

BAILEY, C.; GATRELL, A.C. Interactive spatial data analysis. Upper Saddle River: Prentice Hall, 1996. $432 \mathrm{p}$.

BAKER, W.L. A review of models of landscape change. Landscape Ecology, Dordrecth, v.2, n.2, p.111-133, mar. 1989.

CAMARA, G.; MONTEIRO, A.M.; DRUCK, S.; CARVALHO, M.S. Análise espacial de áreas. In: DRUCK, S.; CARVALHO. C.; CÂMARA, G.; MONTEIRO, A.M.V. (Org.). Análise espacial de dados geográficos. Brasília: EMBRAPA, 2004.

CANASAT. Disponível em: <www.inpe.br/canasat>. Acesso em: 26 jan. 2009.

IBGE. INSTITUTO BRASILEIRO DE GEOGRAFIA E ESTATÍSTICA. Censo demográfico e contagem da população. Disponível em: <www.sidra.ibge.gov.br〉. Acesso em: 12 dez. 2009.

NOVAES, M.R.; AGUIAR, D.A.; RUDORFF, B.F.T. Análise espacial de indicadores socioeconômicos na compreensão do manejo da colheita da cana-de-açúcar. In: ENCUENTRO DE GEÓGRAFOS LATINOAMERICANOS, 13., 2009. Anais... Montevidéu: EGAL, 2009.

ROSEIRO, M.N.V.; TAKAYANAGUI, A.M.M. Meio ambiente e poluição atmosférica: o caso da cana-de-açúcar. Revista Saúde, Natal, v. 30, n. 1-2, p. 76-83, 2004. 